\title{
Locating Water Desalination Facilities for Municipal Drinking Water Based on Qualitative and Quantitative Characteristics of Groundwater in Iran's Desert Regions
}

\author{
M. Habibi Davijani • A. Nadjafzadeh Anvar • M. E. Banihabib
}

Received: 25 November 2013 / Accepted: 15 May 2014 /

Published online: 31 May 2014

(C) The Author(s) 2014. This article is published with open access at Springerlink.com

\begin{abstract}
Groundwater resources have become the main resources for water supply due to the unavailability of surface water in arid zones. Arid zone's damage to groundwater resources will have a high impact on human life in arid zones comparing to other regions. Due to the lack of surface water resources in these arid zones, groundwater is used as a resource for drinking and sanitation purposes due to the lack of surface water resources in these arid zones. Water desalination facilities are set up in locations where there is both sufficient amount of water (quantitative criteria) and the extracted water has adequate quality (qualitative criteria). Therefore, an optimization model should be used to locate optimal places for water desalination facilities. Multi-criteria decision-making models are mathematical techniques that, by using the geographic information system, are able to evaluate the options under complicated and indefinite geographic conditions. This research prepares information and factor maps to assign weights to qualitative water maps which were combined in the form of an inductive network. Therefore, by employing the concept of fuzzy fusion models, this article presents a method for solving multi-criteria geographically-indeterminate problems, and finally finds an appropriate location for the construction of a water desalination system in the desert region of Birjand in Iran.
\end{abstract}

Keywords Water desalination system · Municipal drinking water - Groundwater quality · Groundwater quantity $\cdot$ Fuzzy fusion models

\footnotetext{
A. Nadjafzadeh Anvar ( $₫)$

Department of Civil and Environmental Engineering, Politecnico di Milano University, Milano, Italy e-mail: amir.nadjafzadeh@polimi.it

M. Habibi Davijani • M. E. Banihabib

Department of Irrigation and Drainage, University of Tehran, University College of Abureyhan, Tehran, Iran

M. Habibi Davijani

e-mail: davijanii@gmail.com

M. E. Banihabib

e-mail: Banihabib@ut.ac.ir
} 


\section{Introduction}

Access to clean and safe water is fast becoming a major problem throughout the world. Presently, about 1.2 billion people around the world don't have access to adequate amounts of clean water (World Health Organization 2009). Many people encounter water shortages during hot seasons. The current population growth rate and increase of the earth's surface temperature is causing the problem of access to safe and clean water for drinking and sanitation to become considerably worse (United Nations World Water 2009).

Also groundwater salinization occurs in some some aquifers around the world (Benavente et al. 2004; Barlow 2003). In this context many studies have been conducted with groundwater contamination sources, such as: deep brines or upward flow from deep saline water (Vengosh et al. 1999), downward leakage from surficial saline water through failed or improperly constructed (Aunay et al. 2006), fossil seawater (Yamanaka and Kumagai 2006), Impact of land disposal of reject brine from desalination plants on soil and groundwater (Mohameda et al. 2005), evaporite dissolution (Pulido-Leboeuf et al. 2003) or present seawater intrusion often due to excessive pumping (Kim et al. 2003).

Due to the poor and inadequate potential of surface waters; optimal planning, management and utilization schemes should be implemented in order to supply the needed water from the limited potential of groundwater aquifers (Edet 1993; Gallardo et al. 2005; Partey et al. 2010; Bohlke 2002; Celik and Yildirim 2006; Robins 2001; Gallardo and Tase 2005; Mishra et al. 2005; Edmunds et al. 2003). Considering these conditions, one of the primary means of acquiring clean and safe drinking water in the desert regions is the use of water desalination facilities. The locations and types of these facilities should be selected based on the aquifers' quality limitations with respect to salinity, heavy metals, water hardness and the requirements associated with the improvement of obtained water quality (Aiuppa et al. 2003; Barker et al. 1998; Sanches-Martos et al. 2001; Van Vliet and Zwolsman 2008).

Among a total number of 145 national water desalination units surveyed in towns and villages, 128 units $\left(88.3 \%\right.$ ) with total daily production capacity of $53,317 \mathrm{~m}^{3}$ are located in towns, and the rest of those, with daily production capacity of $6,170 \mathrm{~m}^{3}$, are located in rural regions. The water quality achieved by the water desalination units is a mixture of calcic chloritic sulfates, and the efficiency of these systems in reducing the water's TDS is $98.7 \%$ (Ghanad 2005; Masoomi et al. 2011).

In the group of water desalination units in the desert regions, the quality of raw water changes from sodic sulfates to a mixture of sodic bicarbonates and sodic chlorides in the desalinated water. During 1970s, water desalination systems that worked by Electrodialysis (ED) and reverse osmosis (RO) techniques were introduced to the market. These systems have been considered as viable options in meeting the water shortage challenges in the 21 st century. Regarding the types of desalination processes used in Iran (Fig. 1), it can be mentioned that the RO process is in the first place with a share of $76.5 \%$ (111 units), followed by the multistage flash evaporation (MSF) process with a share of $13.8 \%$ (20 units). The multi-stage distillation (MED) system and mechanical vapor compression (MVC) process, each with $4.15 \%$ of the share (6 units) have occupied the lower ranks (Ghanad 2005; Masoomi et al. 2011). Considering the above information, it can be understood that the use of water desalination systems in Iran is on the rise. Therefore, proper planning and management in the selection of optimal locations for water desalination facilities constitutes the most important factor in achieving the right amount and quality of produced water, and in reducing the operating and maintenance expenses associated with desalination equipment.

Sophocleous et al. (1982) performed a geostatistical analysis on water levels in places where the studied wells were located along the same line and at equal distances from one another, and 

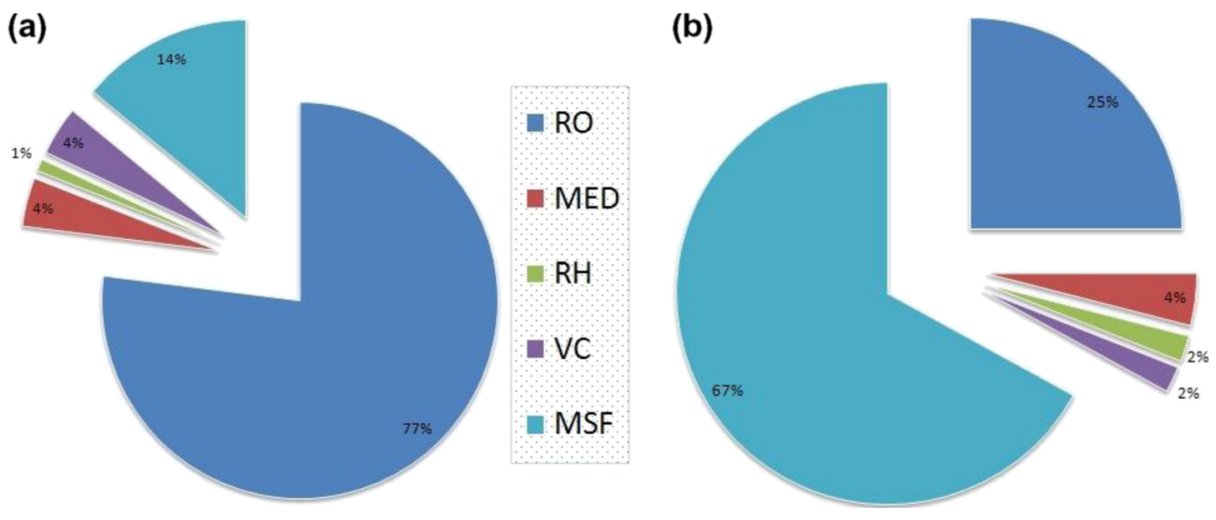

Fig. 1 Types number (a) and production capacities (b) of water desalination plants in Iran's towns

they observed a strong positional correlation between water levels in the wells. They also prepared counter lines maps of groundwater and presented a network for the management of these waters (Sophocleous et al. 1982). Similarly, in a research on the distribution of nitrate concentration in groundwater using the multi-variable statistical analysis method, Raiber et al. (2012) found out that, petrologically, the composition of bedrock has a significant effect on the concentration of nitrate, and concluded that this method can be employed for the analysis of hydrogeological and hydrogeochemical data obtained from studies to locate the spread of water contamination, and that acceptable solutions can be achieved through this approach (Raiber et al. 2012). Güler et al. (2012) used the fuzzy clustering, multivariate statistics and GIS methods, and by means of the hydrological and hydrochemical data on groundwater they could discover the impacts of human activities on these resources. These investigators claimed that human activities have the most devastating impact on the contamination of the studied region (Carter and Graeme 1994; Güler et al. 2012).

As previously mentioned, the use of desalination facilities to remove the salt and purify the groundwater to a drinkable level can be a viable solution to the shortage of safe, drinkable water and lack of access to suitable surface waters in arid zones. Previous research has not paid special attention to locating water desalination facilities to provide municipal drinking water.

In this investigation we consider both the quantitative and qualitative characteristics of groundwater to present a comprehensive method for finding optimal locations for desalination units.

\section{Materials and Methods}

\subsection{The Investigated Region}

The study region of Birjand is part of the Loot desert in Iran. The province of southern Khorasan (where the study plain of Birjand is located) has been situated to the north of Bagheran heights. This plain is roughly rectangular in shape, is surrounded by mountain heights all around, and the alluvial aquifer forms its central zone (Fig. 2). This region has approximately an average length of $131 \mathrm{~km}$ and an average width of $26 \mathrm{~km}$. Its area, based on a digital map with the scale of 1:250000, is about $3,425 \mathrm{~km}^{2}$ and its perimeter is $313.8 \mathrm{~km}$. Average rainfall in this area amounts to $170 \mathrm{~mm}$ per year.

Also, the average annual rainfall in the plain (with an area of $1,383 \mathrm{~km}^{2}$ ) is about $138.29 \mathrm{~mm}$ and the average annual rainfall in the surrounding heights (with an area of 
$2,042 \mathrm{~km}^{2}$ ) is $181.5 \mathrm{~mm}$. This research uses the qualitative groundwater data of Birjand plain (2009) provided by the Birjand Regional Water Organization which pertained to wells and kanats (subterranean kanats), 38 data sources (wells and kanats) were deemed as appropriate in terms of accuracy and sufficiency. More than $90 \%$ of the water needed by the city of Birjand and the area under investigation is supplied by kanats, wells, springs and drainage from groundwater sources. The groundwater basin in this plain, which is separated from the neighboring groundwater basins by the peripheral mountain heights, is divided into the northern section (Merek plain) and southern section (Birjand plain) due to the protrusion of neon facies.

\subsection{Review of Data Normality}

The use of geostatistical methods requires a strong positional correlation among data, which is evaluated by variogram analysis. The normality of data is a condition for the implementation of this analysis; and the Kolmogorov-Smirnov test can be used to investigate this condition. The Kolmogorov-Smirnov test measures how well a general sample distribution follows a particular distribution. The statistic of this test constitutes the largest difference between the expected and real frequencies (as absolute values) measured among the different classes of groundwater qualitative parameters. This statistic is written as follows:

$$
D=\operatorname{Max} \cdot|\mathrm{F}(\mathrm{x})-\widehat{\mathrm{F}}(\mathrm{x})|
$$

Where $\mathrm{F}$ is the real relative cumulative frequency of groundwater qualitative parameters and $\widehat{\mathrm{F}}$ is the expected relative cumulative frequency in these parameters. To perform this test, the following steps are taken. The relative cumulative frequency of a sample is measured for different

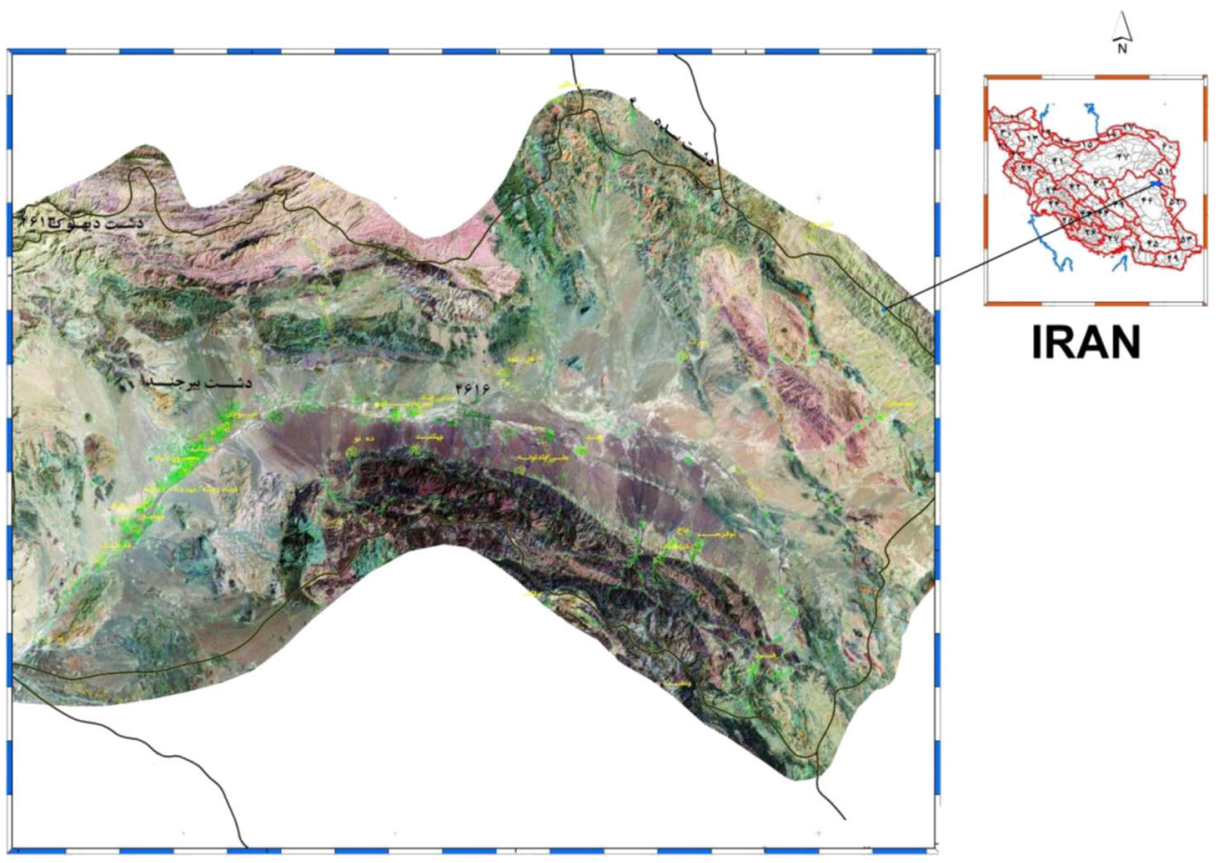

Fig. 2 Landsat satellite image of Birjand plain, Iran 
intervals. The relative cumulative frequency for various classes is determined by means of the theoretical statistical distribution or by using other sample information. For each interval, the absolute value of the difference of two frequencies is calculated through Eq. (1). The maximum difference obtained from each step is recorded as test statistic $D$. Having chosen an error value $\alpha$, and for $n$ number of samples, the amount of $D \alpha$ is read from the statistical table of error and sample size. If $D$ is less than the $D \alpha$ value obtained from the table, then the assumption of sample obeying the considered distribution will be accepted; otherwise, the assumption will be rejected. Any parameter which fails this test does not possess the necessary conditions for normality, and therefore should be converted to a normal time series through one of the computational functions of log normal, gamma function and Box-Cox transforms function.

\subsection{Variogram Fitting}

A variogram is used to express the spatial continuity of a variable. Determining the value of theoretical variogram function is necessary in this research in order to evaluate data continuity. The more carefully this function is selected for the region under study, the more accurate the estimation of parameters will be. The process of selecting an appropriate variogram has several stages, which starts by examining an empirical variogram on observed information. Then a variogram model from the variograms presented for being fitted on the empirical variogram is selected and the parameters of this model are so chosen as to have the best fit on the existing information. For example, we may use a linear variogram as $\mathrm{r}(\mathrm{h})=\theta \mathrm{h}$ to express the experimental variogram and then determine parameter $\theta$ for a better and more proper fit on the information. Considering the empirical variogram, an exponential model such as the following equation has been used for fitting on this information.

$$
\gamma(\mathrm{h})=\mathrm{c} \cdot\left[1-\exp \left(\frac{-\mathrm{h}}{\mathrm{r}}\right)\right]
$$

\subsection{Conversion of Point Information to Regional Information}

In many occasions, due to different reasons such as the lack of measuring stations and the high cost of constructing these stations, the needed information is not available for all the desired points of a groundwater aquifer. To estimate the information pertaining to unmeasured points of a region, the so-called geostatistical methods are used. Geostatistics constitutes the collective studies of phenomena that vary with time and place. This technique can stochastically model the temporal and spatial aspects of a phenomenon. Geostatistical methods work on the basis of estimating an unknown value $\mathrm{z}$ as a random number with a specific probabilistic distribution at an arbitrary point of the space being studied. Two types of frequently-used geostatistical methods are the Kriging method and the method of assigning inverse distance weights.

\subsection{Kriging Method}

Kriging is a set of linear regression methods generalized to large dimensions. Based on the way the problem is treated, the Kriging method can be divided into temporal and spatial types, although the temporal models mostly accompany the spatial solution of the problem as well. Therefore a division between spatial and temporal models can be considered for the Kriging approach. The positional Kriging can be employed for the estimation of a variable at a point 
whose information has not been measured. This method can also be used to find the best network for the measurement of hydrologic variables by adding new measuring stations to the existing network. The simple form of Kriging, known as the ordinary Kriging (Eq. 3), exists based on the first order analysis of $\mathrm{Z}(\mathrm{x})$, and is independent of point $\mathrm{x}$.

$$
\mathrm{E}[\mathrm{z}(\mathrm{x})]=\mathrm{m}
$$

Or if there is a known function such as $\mathrm{m}(\mathrm{x})$ under the conditions of Eq. (4):

$$
\mathrm{E}[\mathrm{Z}(\mathrm{x})]=\mathrm{m}(\mathrm{x})
$$

Variable $\mathrm{Y}(\mathrm{x})$ can be used as Eqs. (5) and (6):

$$
\begin{gathered}
\mathrm{Y}(\mathrm{x})=\mathrm{Z}(\mathrm{x})-\mathrm{m}(\mathrm{x}) \\
\mathrm{E}[\mathrm{Y}(\mathrm{x})]=0
\end{gathered}
$$

For all the vectors of $\mathrm{h}$, component $[\mathrm{Z}(\mathrm{x}+\mathrm{h})-\mathrm{Z}(\mathrm{h})]$ has a limited variance, which is independent of X (Eq. 7):

$$
\operatorname{Var}[\mathrm{Z}(\mathrm{x}+\mathrm{h})-\mathrm{Z}(\mathrm{h})]=2 \gamma(\mathrm{h})
$$

Function $\gamma$ is called a variogram. The first step in Kriging calculations is the calculation of variogram. Kriging equations are divided into different types based on the output (point Kriging and block Kriging) or based on the computational structure; which in this article, the ordinary Kriging equations have been used. In these equations, the average value is assumed as unknown and independent of the coordinates of the region under investigation.

\subsection{Method of Inverse Distance Weights (IDW)}

The second method of geostatistical models is the method of inverse distance weights. In this method, the weights are assigned based on the inverse of distance to the estimated point. In other words, more weights are assigned to the closer samples and less to the samples at farther distance. In the weighted moving average method, the value of weight factor $\left(\lambda_{i}\right)$ is calculated by the following equation:

$$
\lambda_{i}=\frac{D_{i}^{-\alpha}}{\sum_{i=1}^{n} D_{i}^{-\alpha}}
$$

In which, $D_{i}$ is the distance between the estimated point and the value observed at point i, $\alpha$ is the equation power and $n$ is the number of observed points. By using an evaluation method and obtaining the existing errors, one of the above methods that has a better fit on our model is selected and then the factor maps are prepared based on the selected approach.

\subsection{Evaluation of Methods}

In evaluating the geostatistical methods, the cross validation process is mostly used (Güler et al. 2012). In this process, first, the empirical variogram is calculated from the information on qualitative parameters and the theoretical variogram is fitted on them. Then, using the selected 
and fitted model and the Kriging equations and IDW, the value of variable $z\left(x_{i}\right)$ is measured at every point, and by omitting this value from the rest of the information, $z\left(x_{i}\right)$ is estimated. This procedure is repeated for all the measured points. Finally, by using the obtained results, the following three statistics are estimated:

a) Mean Error (ME), which is calculated from Eq. (9):

$$
M E=\frac{1}{N} \sum_{i=1}^{n}\left\{Z\left(X_{i}\right)-\widehat{Z}\left(X_{i}\right)\right\}
$$

In Eq. (9), $\mathrm{Z}\left(x_{i}\right)$ is the real value of information at point $X_{i}, \widehat{\mathrm{Z}}\left(X_{i}\right)$ is the estimated value of information, and $\mathbf{N}$ is the number of points with measurements.

b) Mean Squares Error (MSE), which is calculated by Eq. (10):

$$
M S E=\frac{1}{N} \sum_{i=1}^{n}\left\{Z\left(X_{i}\right)-\widehat{Z}\left(X_{i}\right)\right\}^{2}
$$

c) Mean Squares Deviation Ratio (MSDR), which is obtained from Eq. (11) based on the mean squares error, Kriging variance and IDW:

$$
M S D R=\frac{1}{N} \sum_{i=1}^{n} \frac{\left\{Z\left(X_{i}\right)-\widehat{Z}\left(X_{i}\right)\right\}^{2}}{\widehat{Q}^{2}\left(X_{i}\right)}
$$

Ideally, the value of mean error should be equal to zero, because the Kriging and IDW is an unbiased model. This criterion, by itself, is not a suitable measure; because it is not sensitive to the existing inaccuracies of the variogram. If the selected theoretical variogram is an appropriate model, the MSE will be equal to the obtained variance, and the MSDR will be one (1).

\subsection{Implementation of the Fuzzy Logic Model}

Based on the theory of fuzzy sets, a fuzzy set is a subset which the membership value of its elements in the main set, with respect to a membership function, is between zero (0) and one (1) (Güler et al. 2012). When combining the factors, the single classes and location units existing in each of the factors constitute the elements of the subset, and the criterion for their membership in the desirable set (proper locations for the construction of water treatment units) is how suitable or unsuitable they are, which is determined with a membership degree from 0 to 1 . Each existing class or information unit in a factor has a membership degree between 0 and 1 , which indicates in every factor, the value and importance of a location unit relative to other units and of a single factor relative to other factors. The membership level of each class and location unit, like the weights in the index overlapping method, is determined through expert opinion and the knowledge of data By employing the fuzzy operator the desired combining operations are implemented.

The fuzzy operator known as fuzzy "GAMMA $(\gamma)$ " is used to fuse the sets of factors. Ultimately, by applying the fuzzy operator, the location units of the output map will get their membership degrees (Xiao et al. 2007). This operator represents a general form of fuzzy "sum" 
and "product" operators. Fuzzy "GAMMA $(\gamma)$ " is used when some of the factors have a reducing effect and some others have an increasing effect. In locating water desalination facilities, due to the increasing effect of qualitative and infrastructure factors, and the unknown effects of the environment and natural factors, the fuzzy $\gamma$ operator has been selected for decision-making and evaluation purposes (Wanga and Chang 1995; Chen et al. 2008).

\subsection{Method of Scoring Qualitative Parameters in the Fuzzy Logic Model}

For scoring in the fuzzy logic model, the minimum and maximum values of physical and chemical tests of raw water in each of the parameters (Tables 1 and 2) are used. Thus, in the preparation of factor maps, before the operators are used, scoring should be performed. In this reverse scoring process based on numbers from 1 and 10, the location with the best quality will get a score of 1 and the location with the worst quality will score a 10 . If the quality of a parameter at a location is more than the maximum value in a range mentioned in the table, that location will still get a score of 10. In the prepared maps, the locations with scores of 1 (highest score) and 10 (lowest score) are shown with totally white and totally dark colors, respectively. After obtaining these factor maps, and applying the proper fuzzy operators, the fuzzy combination map of the aquifer's qualitative characteristics could be prepared. Finally, by using the aquifer's counter lines maps and the fuzzy fusion map of qualitative features, the optimal location for the establishment of a water desalination plant to provide municipal drinking water can be found.

Table 1 Physicochemical test results of raw water (well distribution network) water desalination facilities located in towns and villages (Ghanad 2005)

\begin{tabular}{|c|c|c|c|c|c|c|}
\hline Factor & Unit & Number & Minimum & Maximum & Average & Standard deviation \\
\hline Water temp. during testing & ${ }^{\circ} \mathrm{C}$ & 10 & 22.8 & 36 & 27.69 & 4.62 \\
\hline Electrical conductance & Umhos/cm & 17 & 1,362 & 6,910 & 3233.77 & 1666.5 \\
\hline $\mathrm{pH}$ & - & 17 & 5.98 & 7.8 & 7.4 & 0.613 \\
\hline Turbidity & NTU & 9 & 0.09 & 8.5 & 2.7 & 2.9 \\
\hline Total dissolved solids & $\mathrm{mg} / 1$ & 14 & 1,000 & 4,270 & 1959.64 & 1049.58 \\
\hline Basicity & $\mathrm{mg} / \mathrm{l}-\mathrm{CaCO} 3$ & 17 & 65 & 436 & 252.59 & 117.368 \\
\hline Total hardness & $\mathrm{mg} / \mathrm{l}-\mathrm{CaCO} 3$ & 17 & 355 & 1,500 & 828.27 & 409.4 \\
\hline $\mathrm{Ca}$ & $\mathrm{mg} / \mathrm{l}$ & 17 & 41.2 & 484 & 219.3 & 139.28 \\
\hline $\mathrm{Mg}$ & $\mathrm{mg} / 1$ & 17 & 20.8 & 192 & 67.6 & 45.46 \\
\hline $\mathrm{Na}$ & $\mathrm{mg} / \mathrm{l}$ & 13 & 100 & 628 & 333.61 & 150.42 \\
\hline $\mathrm{K}$ & $\mathrm{mg} / \mathrm{l}$ & 8 & 3.35 & 19.05 & 11.36 & 5.35 \\
\hline $\mathrm{HCO}_{3}^{-}$ & $\mathrm{mg} / 1$ & 7 & 200 & 500.2 & 359.16 & 98.9 \\
\hline $\mathrm{Cl}^{-}$ & $\mathrm{mg} / 1$ & 17 & 142 & 1304.6 & 558.306 & 321.233 \\
\hline $\mathrm{Mn}$ & $\mathrm{mg} / \mathrm{l}$ & 1 & 0.3 & 0.3 & 0.3 & 0.3 \\
\hline $\mathrm{NH}_{3}$ & $\mathrm{mg} / 1$ & 5 & 0.06 & 3.2025 & 2.07 & 1.25 \\
\hline $\mathrm{PO}_{4}{ }^{3}$ & $\mathrm{mg} / 1$ & 3 & 0.02 & 0.81 & 0.3097 & 0.435 \\
\hline F & $\mathrm{mg} / 1$ & 2 & 0.2 & 1.02 & 0.61 & 0.579 \\
\hline $\mathrm{SO}_{4}{ }^{2-}$ & $\mathrm{mg} / 1$ & 13 & 180 & 1,517 & 621.8 & 483.974 \\
\hline $\mathrm{Fe}$ & $\mathrm{mg} / \mathrm{l}$ & 1 & 0.14 & 0.14 & 0.14 & 0.14 \\
\hline $\mathrm{NO}_{3}^{-}$ & $\mathrm{mg} / 1$ & 12 & 11 & 297 & 74.724 & 100.149 \\
\hline $\mathrm{NO}_{2}^{-}$ & $\mathrm{mg} / 1$ & 12 & 0.01 & 0.217 & 0.1211 & 0.0678 \\
\hline
\end{tabular}


Table 2 Kolmogorov-Smirnov test results

\begin{tabular}{lllll}
\hline Parameter & Mean & Std. Deviation & Kolmogorov-Smirnov & $\begin{array}{c}\text { Asymp. Sig. } \\
\text { (2-tailed) }\end{array}$ \\
\hline $\mathrm{Mg}$ & 11.005 & 6.225 & 0.494 & 0.968 \\
$\mathrm{Ca}$ & 6.153 & 3.391 & 0.717 & 0.683 \\
$\mathrm{Cation}$ & 45.460 & 24.018 & 0.534 & 0.938 \\
$\mathrm{So} 4$ & 10.102 & 9.047 & 0.174 & 0.010 \\
$\mathrm{Cl}$ & 29.882 & 18.024 & 0.139 & 0.458 \\
$\mathrm{Hco3}$ & 5.105 & 1.634 & 0.896 & 0.398 \\
$\mathrm{Anion}$ & 45.089 & 23.611 & 0.480 & 0.975 \\
$\mathrm{pH}$ & 7.538 & 0.255 & 0.547 & 0.926 \\
$\mathrm{TDS}$ & 2921.434 & 1577.206 & 0.496 & 0.967 \\
$\mathrm{EC}$ & 4427.947 & 2346.374 & 0.532 & 0.940 \\
$\mathrm{~K}$ & 1.045 & 1.157 & 0.186 & 0.010 \\
$\mathrm{Na}$ & 27.257 & 17.214 & 0.709 & 0.696 \\
$\mathrm{CR}$ & 0.497 & 0.024 & 0.316 & 0.054 \\
\hline
\end{tabular}

*Parameters So4 and K don't have normal distributions

\section{Results and Discussion}

Results of physicochemical tests show More than $71 \%$ (99 units) of the desalination units surveyed in Iran's central towns and desert regions are supplied by wells. A review of the quality of raw water in these units (Table 1) indicates that the average values of nitrates $(74.7 \mathrm{mg} / \mathrm{l})$, sulfates $(621.8 \mathrm{mg} / \mathrm{l})$, magnesium $(67.7 \mathrm{mg} / \mathrm{l})$ and TDS (1959.6 mg/l) are higher than the maximum allowed values printed in the national standards; and that based on the "Souline" criteria, the dominant water type is classified in the sodic sulfate group. It can also be stated here that, following the desalination process, the dominant water type changes to a mixture of sodic bicarbonates and sodic chlorides. In the latter state, the $\mathrm{pH}$ values are less than the desirable national standard range, and approach the acidic and corrosive values. Based on the nutritional value of water, the hardness, calcium and magnesium values of water obtained from each of these units are even less than the

Table 3 Results of variogram analysis

\begin{tabular}{llllll}
\hline Parameter & Fractional impact $(\mathrm{co})$ & Threshold $(\mathrm{co}+\mathrm{c})$ & Impact radius & Model & Regression coefficient \\
\hline $\mathrm{Mg}$ & 31.19085 & 31.19085 & 51221.424 & Linear & 0.23 \\
$\mathrm{Ca}$ & 12.02117 & 12.74492 & 51221.424 & Linear & 0.23 \\
$\mathrm{Cation}$ & 626.67252 & 626.67252 & 51221.424 & Linear & 0.65 \\
$\mathrm{So} 4$ & 0.0852 & 0.0852 & 51221.424 & Linear & 0.45 \\
$\mathrm{Cl}$ & 332.69103 & 332.69103 & 51221.424 & Linear & 0.85 \\
$\mathrm{hco3}$ & 1.339 & 3.129 & 150900 & Spherical & 0.94 \\
anion & 600.82275 & 600.82275 & 51221.424 & Linear & 0.66 \\
$\mathrm{pH}$ & 0.0363 & 0.1566 & 147500 & Spherical & 0.92 \\
$\mathrm{TDS}$ & 2708815.171 & 2708815.171 & 51221.424 & Linear & 0.44 \\
$\mathrm{Ec}$ & 5320000 & 10641000 & 211000 & Exponential & 0.76 \\
$\mathrm{~K}$ & 0.35124 & 0.35124 & 51221.424 & Linear & 0.37 \\
$\mathrm{Na}$ & 271.2 & 542.5 & 211000 & Exponential & 0.78 \\
\hline
\end{tabular}


Table 4 Evaluation of the results of estimation methods

\begin{tabular}{|c|c|c|c|c|c|c|}
\hline \multirow[t]{2}{*}{ Parameter } & \multicolumn{3}{|l|}{ KRIGING } & \multicolumn{3}{|l|}{ IDW } \\
\hline & $\mathrm{ME}$ & MSE & MSDR & $\mathrm{ME}$ & MSE & MSDR \\
\hline $\mathrm{Mg}$ & -0.33766 & 37.87505 & 46.69199 & -0.19819 & 44.58582 & 7.785472 \\
\hline $\mathrm{Ca}$ & -0.07122 & 14.71365 & 24.91924 & 0.124129 & 14.93473 & 5.778307 \\
\hline Cation & -0.84755 & 736.8137 & 12.82011 & 0.295551 & 750.4794 & 5.958393 \\
\hline So4 & -0.01954 & 0.110823 & 11.33886 & -0.00312 & 0.112374 & 7.318134 \\
\hline $\mathrm{Cl}$ & -0.85274 & 378.1739 & 25.04366 & -0.58789 & 403.1476 & 5.497253 \\
\hline hco3 & 0.036212 & 2.110365 & 15.77482 & 0.006246 & 2.034184 & 4.607278 \\
\hline anion & -0.87563 & 703.2866 & 12.80501 & 0.110104 & 719.6829 & 5.748787 \\
\hline $\mathrm{pH}$ & 0.006512 & 0.05601 & 3.069737 & 0.004523 & 0.058625 & 1.892881 \\
\hline TDS & -66.3105 & 3215770 & 17.17391 & -13.4516 & 3383632 & 6.151441 \\
\hline Ec & -72.0353 & 6935138 & 10.8146 & 56.18529 & 6974158 & 5.68166 \\
\hline $\mathrm{K}$ & -0.01943 & 0.405297 & 22.92334 & 0.021702 & 0.427773 & 5.396363 \\
\hline $\mathrm{Na}$ & -0.42525 & 350.607 & 10.00569 & 0.291488 & 357.7355 & 6.028363 \\
\hline
\end{tabular}

recommended values. The minimum and maximum values of each of these parameters can be used in the scoring system of fuzzy logic.

As was previously mentioned, to perform a variogram analysis and to use the geostatistical methods, first, the normality of data should be verified The Kolmogorov-Smirnov test results can be observed in Table 2. Considering a probability level of $95 \%$, it is observed in this table that parameters So4 and K don't follow a normal distribution. So the data of these parameters should be normalized. The simple function of log normal was initially used in order to normalize these two parameters (base $10 \log$ was taken from the data), and the data were tested again for normality using the Kolmogorov-Smirnov test. Parameter K wasn't normalized this way; so this time, the gamma function was used (square root was taken from the data), which ultimately normalized the data of parameter K. Following the normalization of data, the variograms are analyzed. The results of variogram analysis for 12 qualitative parameters have been listed in Table 3. In the potassium, calcium, magnesium and sulfates parameters, there isn't a very strong spatial correlation between the data; while in the rest of parameters, a strong correlation exists between the parameters.

Fig. 3 Position map of 38 water sources (wells and kanats) of the aquifer in Birjand plain, Iran

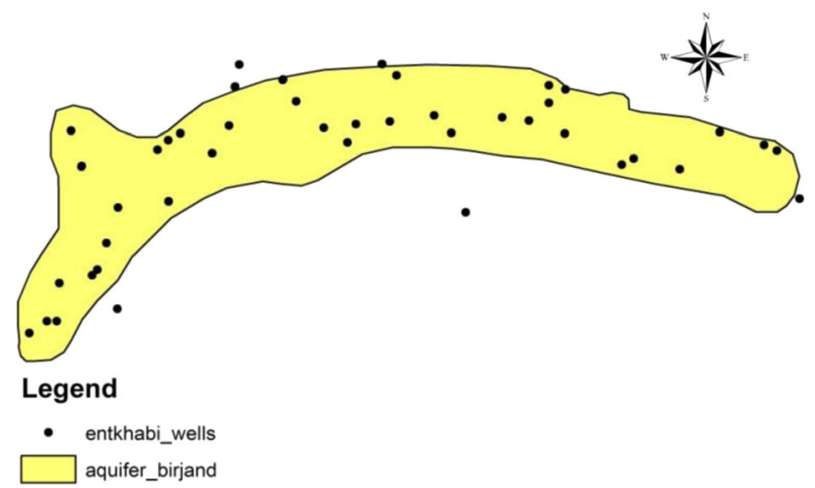


Fig. 4 Fuzzy combination map of the aquifer's qualitative features in Birjand plain, Iran

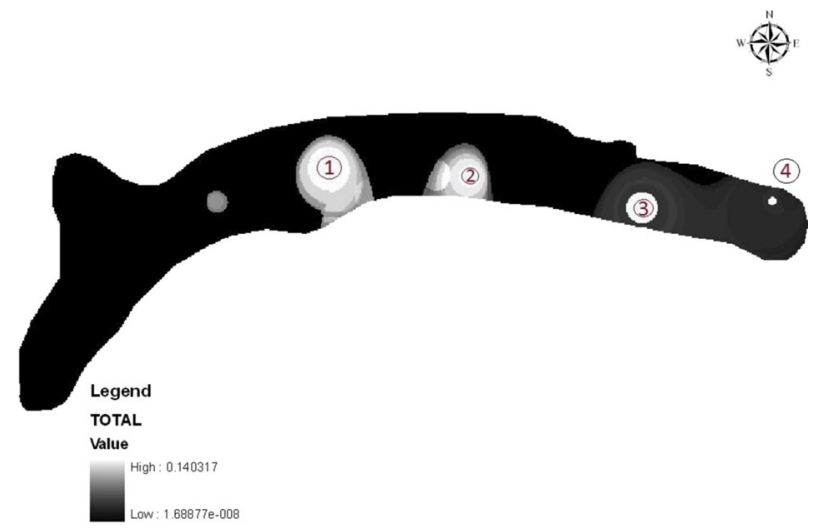

Using the cross validation procedure, first, the empirical variogram was calculated from the information, and the theoretical variogram was fitted on it. Then for both the Kriging and IDW methods, the values of ME, MSE and MSDR were calculated. The obtained results have been listed in Table 4. As is observed in this table, due to lower values of these parameters in the IDW method, this method can be considered as having the best fitting capability for the interpolation purposes. So the IDW technique is selected to complete the present task in the fuzzy method.

After executing the operator (Fuzzy "GAMMA $(\gamma)$ ") in fuzzy logic model, preparing the factor maps and using the IDW method, the model was implemented in the geographic information system based on the qualitative characteristics, and the fuzzy fusion map of aquifer's qualitative features (Fig. 4) was obtained. Also, for quantitative comparisons, the position map of 38 water sources (wells and kanats) of aquifer (Fig. 3) was used in order to plot the aquifer's contour lines map (Fig. 5). This provides the right tools to choose an optimal location that considers that qualitative and quantitative characteristics of groundwater resources.

In view of Fig. 4 which emphasizes the aquifer's qualitative characteristics, four regions with specific boundaries can be delineated as follows: Points with number 1, 2, 3 and 4 that each of these regions has been outlined in the figure with its corresponding number. Except for option number 4, which makes up a small area, the other three options are qualitatively in a good shape. In view of Fig. 5, which shows the ground water levels of the aquifer in the study region, it can be said that in the vicinity of well no. 1, the aquifer's water table is lower than

Fig. 5 Piezometric contour line map of the aquifer in Birjand plain, Iran

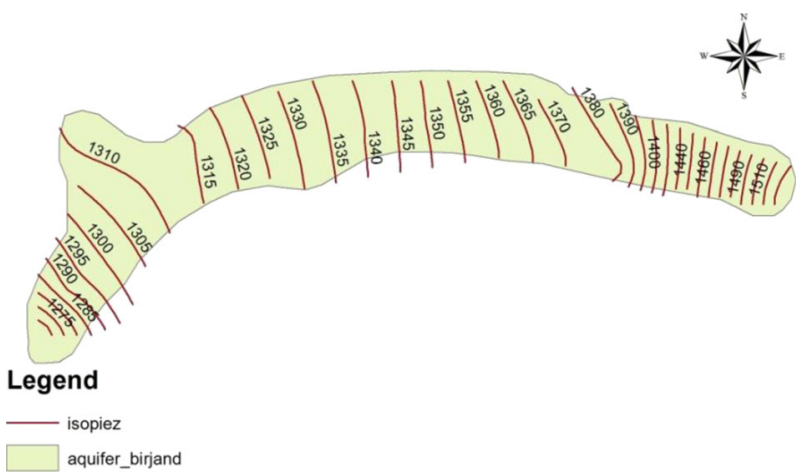


that of the other two options; therefore, it is not a viable choice for the establishment of a water treatment unit. Of the two remaining options (wells no. 2 and 3), the one that has an easier access and also incurs less cost in terms of water transportation should be selected as the optimal location. The best and most economical choice is therefore in the zone of well no.2, situated centrally in the noted region.

\section{Conclusions}

In light of the obtained information, it can be said that the construction of water treatment facilities using the desalination units is on the rise in Iran. It should also be mentioned that proper management in the selection of optimal locations for water desalination facilities is the most significant factor in the amount and quality of water that can be produced and in the reduction of operating and maintenance expenses associated with these facilities. In this research, it was attempted to present a comprehensive and optimized method for finding suitable locations for water treatment (desalination) facilities in Iran's desert regions by considering both the quantitative characteristics (ground water level) and qualitative features (12 parameters of water quality). Therefore, first, the normality of the parameters was evaluated and the non-normal parameters were normalized. Then, the Kriging and IDW models were used to interpolate these parameters. For each parameter, the most appropriate interpolation model was selected. In the next step, the interpolate maps were combined as fuzzy fusion maps. And finally, by considering the comprehensive fuzzy fusion map and the aquifer's contour lines map, a suitable model for locating water desalination facilities was created.

Open Access This article is distributed under the terms of the Creative Commons Attribution License which permits any use, distribution, and reproduction in any medium, provided the original author(s) and the source are credited.

\section{References}

Aiuppa A, Bellomo S, Brusca L, D’Alessandro W, Federico C (2003) Natural and anthropogenic factors affecting groundwater quality of an active volcano (Mt. Etna, Italy). Appl Geochem 18:863-882

Aunay B, Driger N, Duvail C, Grelot F, Le Strat P, Montginoul M, Rinaudo JD (2006) Hydro-socio-economic implications for water management strategies: the case of Roussillon coastal aquifer, International Symposium - DARCY 2006, Aquifer Systems Management, Dijon

Barker AP, Newton RJ, Bottrell SH (1998) Processes affecting groundwater chemistry in a zone of saline intrusion into an urban aquifer. Appl Geochem 13:735-749

Barlow PM (2003) Groundwater in freshwater-saltwater environments of the Atlantic Coast, US Geological Survey

Benavente J, Larabi A, El Mabrouki K (2004) Monitoring, modeling and management of coastal aquifers, University of Granada, Water Research Institute

Bohlke JK (2002) Groundwater recharge and agricultural contamination. J Hydrogeol 10:153-179

Carter B, Graeme F (1994) Geographic Information Systems for Geoscientists: Modelling with GIS. Pergamon Pres, Tarrytown, p 398

Celik M, Yildirim T (2006) Hydrochemical evaluation of groundwater quality in the Cavuscayi Basin, SungurluCorum, Turkey. J Environ Geol 50:323-330

Chen MF, Tzeng GH, Ding CG (2008) Combining Fuzzy AHP with MDS in identifying the preference similarity of alternatives. J Appl Softw Comput 8:110-117

Edet AE (1993) Groundwater quality assessment in parts of eastern Niger Delta, Nigeria. J Environ Geol 22:4146

Edmunds WM, Shand P, Hart P, Ward RS (2003) The natural (baseline) quality of groundwater: a UK pilot study. Sci Total Environ 310:25-35 
Gallardo AH, Tase N (2005) Hydrology and geochemical characterization of groundwater in a typical small-scale agricultural area of Japan. J Asian Earth Sci 29:18-28

Gallardo AH, Reyes-Borja W, Tase N (2005) Flow and patterns of notrate pollution in groundwater: a case study of an agricultural area in Tsukuba City, Japan. J Environ Geol 489:908-919

Ghanad M (2005) Desalination of urban and rural water supply and the quality of their. J Water Environ 64:3-10

Güler G, Kurt MA, Alpaslan M (2012) Assessment of the impact of anthropogenic activities on the groundwater hydrology and chemistry in Tarsus coastal plain (Mersin, SE Turkey) using fuzzy clustering, multivariate statistics and GIS technique. J Hydrol 414:435-451

Kim Y, Lee KS, Koh D-C, Lee D-H, Lee S-G, Park WB, Koh G-W (2003) Hydrogeochemical and isotopic evidence of groundwater salinization in coastal aquifer: a case study in Jeju volcanic island, Korea. J Hydrol 270:282-294

Masoomi Z, Mesgari MS, Menhaj MB (2011) Modeling uncertainties in sodium spatial dispersion using a computational intelligence-based kriging method. J Comput Geosci 37:1545-1554

Mishra PC, Behera PC, Patel RK (2005) Contamination of water due to major industries and open refuse dumping in the steel city of Orissa: a case study, ASCE. J Environ Sci Eng 47(2):141-154

Mohameda AMO, Maraqaa M, Al Handhalyb J (2005) Impact of land disposal of reject brine from desalination plants on soil and groundwater. J Desalination 182:411-433

Partey FK, Land LA, Frey B (2010) Final report of the geochemistry of bitter lakes national wildlife refuge. New Mexico Bureau of Geology and Mineral Resources, Roswell, p 19

Pulido-Leboeuf P, Pulido-Bosch A, Calvache ML, Vallejos A, Andreu JM (2003) Strontium, SO2_4/Cl-and $\mathrm{Mg} 2+/ \mathrm{Ca} 2+$ ratios as tracers for the evolution of seawater into coastal aquifers: the example of Castell de Ferro aquifer (SE Spain). Compt Rendus Geosci 335:1039-1048

Raiber M, White PA, Daughney CJ (2012) Three-dimensional geological modeling and multivariate statistical analysis of water chemistry data to analyse and visualise aquifer structure and groundwater composition in the Wairau Plain, Marlborough District, New Zealand. J. Hydrology. In Press, Accepted Manuscript

Robins NS (2001) Groundwater quality in scotland: major ion chemistry of the key groundwater bodies. J Sci Total Environ 294:41-56

Sanches-Martos F, Pulido-Bosh A, Molina-Sanches L, Vallejos-Izquierdo A (2001) Identi- fication of the origin of salinization in groundwater using minor ions (Lower Andarax, Southeast Spain). Sci Total Environ 297(1 \& 3):43-58

Sophocleous M, Paschetto JE, Olea A (1982) Ground water network design for northwest Kansas, using the theory of regionalized variables. J Ground Water 20:48-58

United Nations World Water Assessment Programme., 2006 [cited Dec. 18, 2009]. the 2nd United Nations World Water Development Report -Water: A Shared Responsibility

Van Vliet MTH, Zwolsman JJG (2008) Impact of summer droughts on the water quality of the Meuse River. J Hydrol 353:1-17

Vengosh A, Spivack AJ, Artzi Y, Ayalon A (1999) Geochemical and boron, strontium, and oxygen isotopic constraints on the origin of the salinity in groundwater from the Mediterranean coast of Israel. Water Resour Res 35:1877-1894

Wanga MJ, Chang TC (1995) Tool steel materials selection under fuzzy environment. Fuzzy Sets Syst 72:263270

World Health Organization and UNICEF, 2006 [cited April 3, 2009]. Meeting the MDG drinking water and sanitation target

Xiao DN, Song D, Yang G (2007) Temporal and spatial dynamical simulation of groundwater characteristics in Minqin Oasis. J Sci China Ser D-Earth Sci 5-2:261-273

Yamanaka M, Kumagai Y (2006) Sulfur isotope constraint on the provenance of salinity in a con.ned aquifer system of the southwestern Nobi Plain, central Japan. J Hydrol 325:35-55 